\title{
SONG STRUCTURE WITHOUT AUDITORY FEEDBACK: EMENDATIONS OF THE AUDITORY TEMPLATE HYPOTHESIS ${ }^{1}$
}

\author{
PETER MARLER ${ }^{2}$ and VIRGINIA SHERMAN
}

Rockefeller University, Field Research Center, Millbrook, New York 12545

Received June 21, 1982; Revised October 1, 1982; Accepted October 8, 1982

\begin{abstract}
Motor patterns of songs of swamp and song sparrows, Melospiza georgiana and M. melodia, deafened early in life display a significant degree of species-specific structure. Normal songs of the two species differ in the degree to which they are segmented. Swamp sparrow song consists of a single segment, and song sparrow songs are multisegmental. Song and swamp sparrows were deafened at 17 to 23 days, prior to the onset of song or subsong. The song sparrows developed more segments in their singing than the swamp sparrows. Species-specific trends were also evident in song durations and frequency characteristics. Abnormalities were found, however, in the morphology of the notes and syllables from which songs of early deafened sparrows are constructed. These results require emendation of the auditory template hypothesis of song learning in birds.
\end{abstract}

The two most obvious means for exerting genetic control over the structure of a vocalization are by inherited patterns of motor outflow from the brain to the soundproducing organs or by innate auditory "templates" to which an organism would match its own voice (Marler, 1964). The development by Schwartzkopff (1949) of a method for extirpation of the cochlea, thus rendering a bird totally deaf, prepared the way for new insights into the decoding of genetic information in behavioral development. Schleidt (1964) used Schwartzkopff's method to deafen young turkeys, Meleagris gallopavo, showing that gobbling developed normally. However, a preliminary investigation of effects of deafening on the social behavior of a songbird, the bullfinch, Pyrrhula pyrrhula, indicated changes in vocal behavior after birds were deprived of auditory feedback (Hüchtker and Schwartzkopff, 1958). In addition, some blackbirds, Turdus merula, deafened by Schwartzkopff for Messmer and Messmer (1956) also displayed some abnormal song characteristics (Thielcke and Thielcke, 1960).

Konishi was the first to explore the impact of deafening on vocal behavior systematically, both prior to song

\footnotetext{
${ }^{1}$ This work was supported by Research Grant MH 14651 and Biomedical Research Support Grant PHS RR07065-15. The authors are much indebted to Dr. Philip Price for performing the deafening operations, and to C. Marler, J. Marler, M. Searcy, and S. Peters for other contributions to the project. M. Konishi made valuable criticisms of the manuscript, and C. Clark and R. Suter advised on statistical problems. We thank the Cary Arboretum of the New York Botanic Garden for providing access to study sites.

${ }^{2}$ To whom correspondence should be addressed.
}

development and after mature song patterns were crystallized. In the domestic chicken, renditions of all normal species' vocal signals were developed by chicks deafened soon after hatching (Konishi, 1963). Similar results have since been obtained for ring doves (Nottebohm and Nottebohm, 1971). In striking contrast, several songbirds studied by Konishi developed highly abnormal song patterns after early deafening, including the American robin, Turdus migratorius, the Mexican junco, Junco phaeonotus, and, most notably, the white-crowned sparrow, Zonotrichia leucophrys (Konishi, 1965a, b).

The innate song of a male white-crowned sparrow reared in social isolation is significantly simpler in structure than normal, but with a number of features in common with the natural song (Marler and Tamura, 1964). Male white-crowns deafened in infancy developed even fewer normal song characteristics (Konishi, 1965b). The same noisy, amorphous song develops whether the deafening occurs before or after exposure to conspecific song, as long as the male's song patterns have not crystallized. This experiment provided the basis for the "auditory template hypothesis" of song learning (Konishi, 1965b). By contrast with early deafening, Konishi (1965b) found with white-crowned sparrows that late deafening, after song crystallization was completed, had almost no impact on song structure.

Both acquired and innate auditory templates for song have been postulated. A white-crowned sparrow typically stores learned songs before reproducing imitations. Konishi (1965b) hypothesized that the learned memory is used template-fashion, as a reference for song development. In addition, innate templates have been invoked 
to explain the fact that the song of an early deafened white-crown is more primitive even than the innate song of a white-crown with hearing intact, reared in social isolation (Marler, 1970; Marler and Tamura, 1964). Such innate templates could also mediate the selective choice of conspecific models for learning demonstrated in several songbirds (Marler, 1970; Marler and Peters, 1980). The concept of innate auditory templates, modifiable through experience, is the focus of the present study (e.g., Marler, 1976). The concept derives support from the highly degraded structure of the song of some early deafened songbirds.

Subsequent to Konishi's work degraded motor patterns of singing developing after early deafening were demonstrated in other oscine birds known to engage in song learning (Nottebohm, 1966, 1967, 1968; Marler et al., 1972; Marler \& Waser, 1977; Price, 1979). However, the extent of the degradation and its significance have remained a matter of controversy. Deaf white-crowned sparrows, Mexican juncos, and robins had highly abnormal songs (Konishi, 1964, 1965a, b), and the same is true of deaf song sparrows, Melospiza melodia (Mulligan, 1966). Deafened Oregon juncos (Junco oreganus) and black-headed grosbeaks (Pheucticus melanocephalus), on the other hand, developed more normal songs, suggesting that some species are able to realize a significant degree of species-specific song structure without auditory feedback (Konishi, 1964, 1965a). There was some variation in the age of deafening of these subjects, however, ranging from 2 weeks to as late as 3 months, raising the possibility that a contributing factor was variation in the amount of predeafening song experience, although Konishi felt that in the case of the contrast between the two junco species this could be excluded (Konishi, 1964).

On the basis of studies of yet another species, the chaffinch, Fringilla coelebs, Nottebohm (1966, 1968) again suggested that apparent species differences in deaf singing might be attributable to incidental differences in the amount of predeafening vocal experience. Experiments on effects of deafening of chaffinches at varying stages of song development indicated that, after a certain stage, they retained song structure achieved prior to deafening (Nottebohm, 1968). Nottebohm advanced the prediction that with deafening of different songbirds at comparable developmental stages the results might coincide more closely with those for the chaffinch. This species produced what was interpreted as a virtually structureless song after early deafening (Nottebohm, 1966, 1968).

The present study set out to resolve this issuc by making detailed comparisons of effects of early deafening on song development in two closely related sparrows, the swamp sparrow, Melospiza georgiana, and the song sparrow, Melospiza melodia, and by using as a frame of reference innate songs developed by the two species with hearing intact. Young of both species were deprived of auditory fecdback at cquivalent stages of vocal development, prior to onset of even the earliest stages of song development.

\section{Materials and Methods}

Two male song sparrows and six male swamp sparrows were collected as 3- to 10-day-old nestlings during the first 2 weeks of June 1978 at the Rockefeller University Field Research Center and the Cary Arboretum, Dutchess County, New York State. They were subsequently reared by hand as a mixed-species group, in isolation from adult song until independence. The birds were deafened bilaterally between 17 and 23 days of age by Dr. Philip Price, under Equithesin anesthesia (Nottebohm, 1968), using the technique of Konishi (1964). The vocal output of all birds was closely monitored prior to deafening. In no case was any subsong produced beforehand. The birds were then housed in the company of intact agemates and exposed to playback of recorded songs iwice a day for a period of 30 days, beginning at about 4 weeks of age. The training songs were composed of natural song and swamp sparrow syllables arranged as: (1) natural song sparrow songs; (2) natural song sparrow song with swamp sparrow substitutions in either the introductory trill, the second phrase trill, or the first note complex; (3) a sequence of unrepeated swamp sparrow syllables. These are described in Marler and Peters (1980, p. 95). The intact birds subsequently produced many imitations of the training patterns. No hint of any correspondence was ever detected in songs of the present subjects, providing independent confirmation that they were indeed totally deaf.

As the birds began occasional subsong in the fall of 1978 , they were moved from groups to individual isolation in soundproof chambers and their songs were recorded. Initial recordings were conducted on an opportunistic basis. When more frequent song commenced at about 9 months of age, weekly recordings were made of each bird, $1 \mathrm{hr}$ in duration, soon after dawn. Numbers of songs recorded and analyzed are given in Table II. Daylengths were changed weekly to approximate those normal for the season. With four of the six swamp sparrows, adequate song samples were difficult to obtain. These birds (Table I) were implanted with a crystalline pellet of testosterone propionate to stimulate song, following the practice of previous investigators of deaf birdsong (Nottebohm, 1966, 1968). All songs were edited from the original recordings and analyzed by real-time sound spectrography using a Princeton Applied Research FFT realtime analyzer, Model 4512. Mean song durations were measured for each recording date, using a Summagraphics Tablet and a PDP 11/10 DEC computer programmed to register song duration to the nearest $12.8 \mathrm{msec}$.

As others have found with deaf birds, they were slow to crystallize song, and it was not easy to determine when the process was completed. In intact swamp sparrows crystallization is accompanied by a sudden reduction in the variability of song duration (Marler and Peters, 1982). On this basis all analyses were reviewed and a type date was chosen for each deaf bird, defined as that date on which the standard deviation for song duration was minimal. An overview of songs on this date provided the basis for delineating song types. Recordings from this date provided the exemplars with which all other songs were compared for purposes of classification.

Distinct song types were defined on the basis of morphological and temporal features. Also, in the mature song of both swamp and song sparrows, song types are sung in bouts. If there was a question about whether a deaf song variant qualified as a distinct type, the final 
TABLE I

Data on the eight experimental subjects, indicating the age at deafening

In every case deafening was prior to the onset of subsong. See the text for an explanation of the "bout transition samples." These typically consisted of five songs per date per song type. For technical reasons some were incomplete, as is indicated. When fewer than four songs per type were available $(* *)$, the sample was supplemented by consecutive songs of the same type from the same date. In birds with large repertoires it was not always possible to locate appropriate bout transitions for every song type. In such cases (*), an equivalent sample of five consecutive songs was taken without reference to bout transitions.

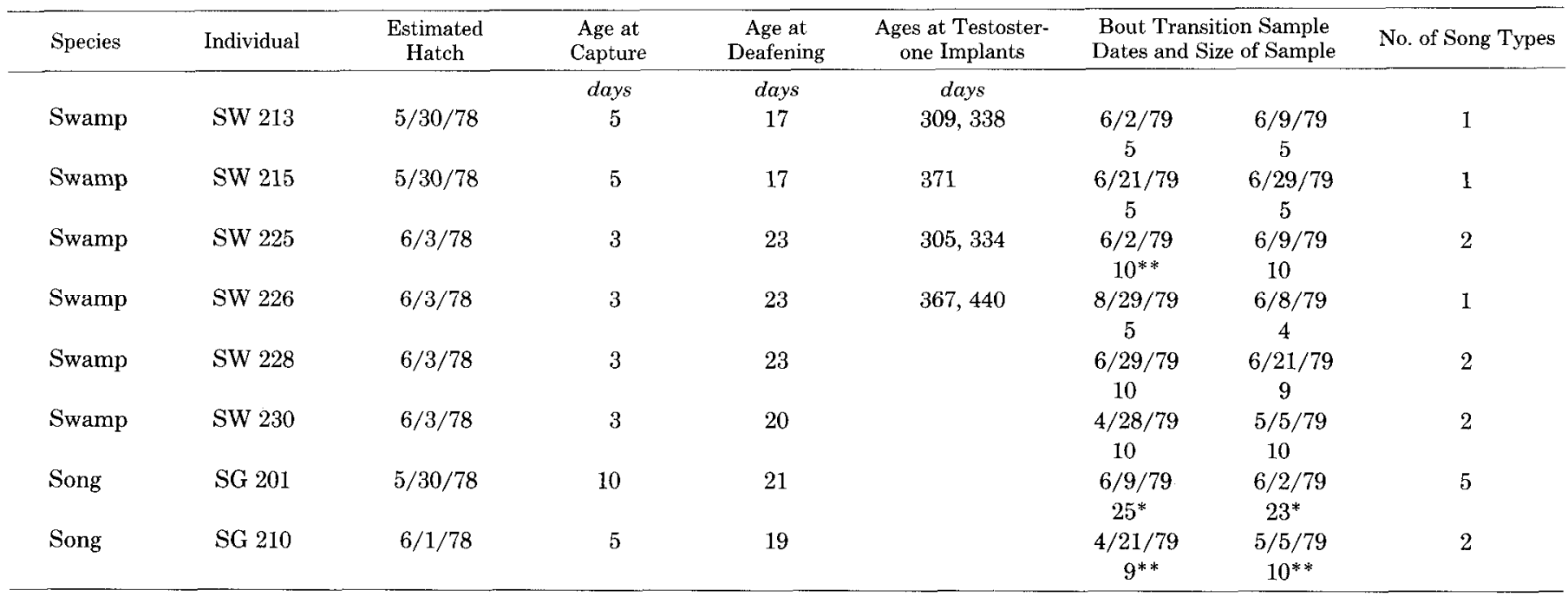

decision was based upon whether it was delivered in bouts. If a song did not fall into any classified song type and was not sung in bouts, it was treated as "unclassifiable."

Wide band $(300 \mathrm{~Hz})$ sound spectrograms were prepared on the Kay Electric sound spectrograph (Model 6061-B) of up to 10 examples of every song type of each bird, as sung on two different dates. When possible one sample of five songs was taken on the type date and the other 7 days later. In selecting songs for analysis, transitions from a bout of one song type to a bout of another were located. Typically 10 consecutive songs were selected. Five immediately preceding the transition and five of the second type following it were selected for further analysis. In a few cases there were unclassifiable songs at the transition. If the eligible total was less than four songs songs the sample was supplemented with consecutive songs of the same type chosen away from the transition. Also with large repertoires it was sometimes difficult to conform to the procedure exactly for all song types. In these cases an equivalent sample of five consecutive songs was taken without reference to a bout transition.

Using the same procedure as for measurement of song duration, note durations and internote intervals were measured on the sound spectrograms, using a $50-\mathrm{Hz}$ calibration tone as the basis for measurement. Traces closer than $1 \mathrm{~mm}$ (about $8 \mathrm{msec}$ ) were considered to be one note. The maximum, minimum, and dominant frequency of each note were measured to the nearest 125 $\mathrm{Hz}$ on a scale derived from a $500-\mathrm{Hz}$ calibration placed on every sonogram.

A crucial step in song analysis was the determination of phrase structure as represented by the number of segments in each song. If a song consisted of identical or similar trilled repetitions of the same acoustic unit throughout, it was classified as a single segment. This is typical of normal swamp sparrow song trills. Wherever distinct segments could be discerned within the song, these were marked and counted. Within a song, a series of similar trilled syllables (a trill) and a block of unrepeated syllables (a note complex) were considered as separate segments (see Fig. 6). Song sparrow songs typically consist of three or four distinct segments, some of them trills and some note complexes (Mulligan, 1966).

To cope with the extreme variability in the acoustic structure of deaf songs, a rule of thumb was adopted in delineating song segments or phrases. The most important features were acoustic morphology and frequency, as displayed on the $80-\mathrm{Hz}$ to $8000-\mathrm{Hz}$ normal speed sound spectrograms of the "bout transition samples." If two succeeding acoustic elements were generally similar in morphology and frequency and satisfied certain duration requirements, they were considered as repeated syllables and regarded as one segment. The duration requirement was satisfied if elements differed in duration by less than $50 \%$. If durations of successive elements varied by more than $50 \%$, they were regarded as different. A group of different, unrepeated components, constituting a note complex, was delineated as a separate segment. For example, if there were notes with similar morphology and frequency and durations of 100, 120, 200 and $320 \mathrm{msec}$, the first two would be considered as one segment and the last two as a separate segment. In the terminology used to segment normal songs, the first segment would qualify as a trill and the second as a note complex (Fig. 6). All sound spectrograms in the bout transition samples of both species were submitted to this segmentation process.

\section{Results}

\section{How stable are the songs of early deafened birds?}

All studies of the impact of early deafening on oscine song development have emphasized the high degree of 


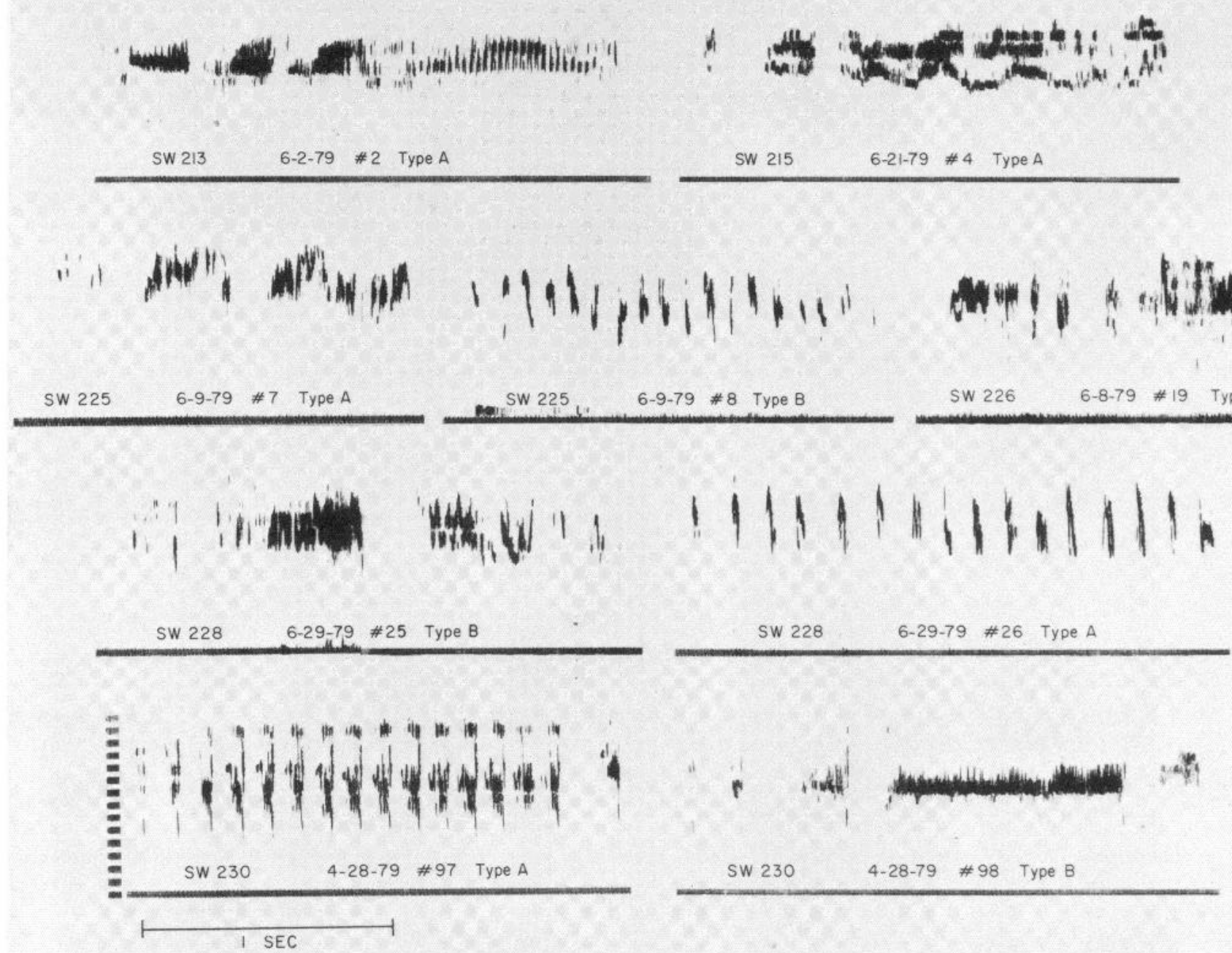

Figure 1. Sound spectrograms of one example of each of the nine song types produced by six early deafened male swamp sparrows, Melospiza georgiana. The three two-song repertoires are all illustrated by consecutive songs, at a transition between bouts of the two song types. The frequency scale is marked in $500-\mathrm{Hz}$ steps. A 1 -sec time marker is included.

variation and instability that the songs exhibit. Figures 1 and 2 show single examples of each of the 16 song types developed by the eight subjects. It is immediately evident that they represent an extraordinarily wide spectrum of morphological types. Those of the swamp sparrows range from pulses of amorphous noise (e.g., SW 215, Type A; $S W 230$, Type B, Fig. 1) or highly erratic, raspy twitters (SW225, Type A; SW226, Type A, Fig. 1) through songs that are irregular but nevertheless display primordial syllabic structure (e.g., $S W$ 213, Type A; SW 225, Type $B$, Fig. 1) to some in which syllables are repeated consecutively with a fair degree of precision ( $S W 228$, Type A; SW 230, Type A, Fig. 1). Note that structured and unstructured song types recur in repertoires of the same bird ( $S W 228$, SW 230, Fig. 1). Similarly, in repertoires of the deaf song sparrows there are some songs consisting entirely or in part of what is essentially a band of noise (e.g., SG 201, Type B, Fig. 2). Others display more internal structure, and some include segments made up of syllabic units that, while never as stable as those of normal song, contain similar units reproduced in a consecutive sequence (e.g., SG 210, Type A, Fig. 2). Once more the same repertoire includes both structured and unstructured song patterns.
Before comparing songs of the two species it is necessary to establish the legitimacy of differentiating distinct themes at all, given their variability. How confident can we be in selecting a sample of songs for detailed analysis that they represent generally used song types, rather than arbitrary samples from continua of randomly varying patterns?

Table II shows the numbers of songs recorded and analyzed by real-time sound spectrography for each subject. In year 1 a total of 4121 songs judged to be crystallized were analyzed and classified by reference to type exemplars. These exemplars were selected from songs recorded on the type date for each bird, determined by reference to the day for each subject on which song duration exhibited the minimal degree of variation, as described under "Materials and Methods." Sample sizes for individual birds range from 97 to 1195 , with a mean of 515 per bird. Examples of subsong and plastic song identified at this time were set on one side and not considered further in the present study. Table II shows the percentage of all recorded songs of each bird, including subsong and plastic song that were judged as conforming to the reference "types," as represented by the samples from the "type-date." Songs that failed to con- 
form to a reference type were designated as "unclassifiable," as contrasted with "Type A" or "Type B" songs and so on.

The percentage of unclassifiable songs for each bird ranged from $1 \%$ to $24 \%$, with an average percentage value of $8.5 \%$. Thus, on average, $91.5 \%$ of the songs of these early deafened sparrows were assignable to reference types. Figure 3 shows four songs uttered by one deaf male swamp sparrow, two consecutive songs in a bout of one type $(A)$ and two consecutive song from a bout of the next $(B)$. Figure 4 shows the same for a deaf song sparrow. In both cases the distinctions between song types are clear and unambiguous. Evidently there is sufficient order in the structure of most songs for different types to be reliably differentiated.

There is, however, a significant proportion of songs that depart widely from the reference types. Although we do not have equivalent quantitative data from intact birds for the occurrence of normal songs that depart from the basic individual repertoire, the proportion of crystallized songs unassignable to a reference type would cer- tainly be less than $1 \%$, and in most subjects there would probably be none at all. Thus, while it is justifiable to base the following analysis on representative song types of each bird, the residue of "unclassifiable" songs probably represents a significant departure from normal singing behavior.

Is it valid to speak of individuality in referring to the song repertoires of early deafened song and swamp sparrows? In the vast majority of cases, a given song type, as displayed on a sound spectrogram, could not be confused with classified song types of any other individual. This was equally true within a species and between species. Interestingly, one song type of song sparrow male 201 displays a resemblance to several of the swamp sparrow songs, thus transgressing the interspecies boundary. A striking example is shown in Figure 8.

\section{Do song types have long term stability?}

In nature it is typical of song and swamp sparrows that the same repertoire is developed in the first and second years. Thus, the brain mechanisms controlling normal
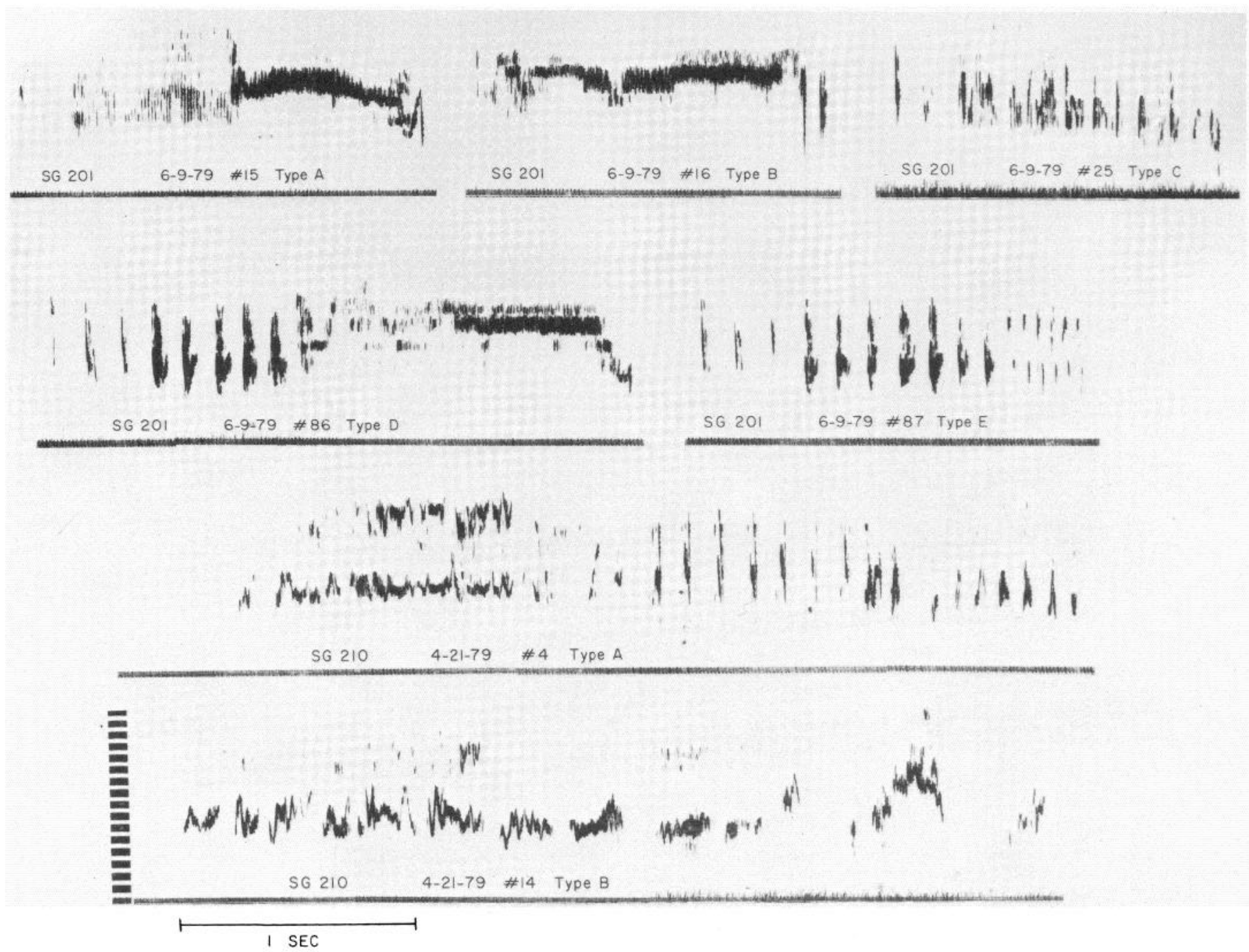

Figure 2. Sound spectrograms of the complete repertoires of two early deafened song sparrows, Melospiza melodia. All songs (except SG 210 \#4) are represented either by the first or the last in a bout of that type. Frequency and time scales are as in Figure 1. 
song retain their ability to generate the same songs through a nonsinging period of up to 9 months in duration (P. Marler and S. Peters, unpublished observation). Is the same true of the songs of early deafened sparrows?

Seven of the eight deaf subjects were studied in their second year. A total of 2003 songs were recorded and analyzed. As shown in Table II, the vast majority were assignable to the same song types as first-year singing. The percentages of unassignable songs were, in fact, lower for all birds except one song sparrow, in which the percentage increased from $11 \%$ to $19 \%$. In the swamp sparrows there were no unassignable songs in the second year. The instability of deaf song sparrow song was somewhat greater. This contrast is probably paralleled by a somewhat higher degree of year-to-year variation in their natural singing behavior (P. McArthur, personal communication). There is also a higher rate of occurrence (approximately 5\%) in intact song sparrows in the laboratory of songs that are unassignable to a type (P. Marler and S. Peters, unpublished observation), as compared with swamp sparrows. Comparisons of first- and secondyear renditions of selected song types are illustrated in Figure 5.

Birds with repertoires of more than one song type retained the same repertoires in the second year, with no new types added. Moreover inspection of Table II reveals that when there were individual preferences for certain items in the repertoire, similar biases occurred in the second year. In the three swamp sparrows with two-song repertoires, first- and second-year preferences for the same song type were $27 \%$ (year 1) and $29 \%$ (year 2), $30 \%$ (year 1) and 35\% (year 2), and $42 \%$ (year 1) and 51\% (year 2 ). Similarly, in the two song sparrows the song types most preferred in the first year (25\% and $76 \%)$ were also the most preferred in the second year $(22 \%$ and $65 \%$, Table II).

Thus, despite the variability in song structure that early deafened swamp and song sparrows display, it is evident that their crystallized singing is, for the most part, organized into song types that exhibit long term stability. Further analysis is based on representative "bout transition" samples of these song types (see "Materials and Methods").

\section{Are the songs of early deafened birds species specific?}

Comparative investigation of these two species, reared under the same conditions, is the basis for addressing the issue of species specificity. The most appropriate controls are songs of birds of the same species reared and maintained under similar laboratory conditions but with their hearing intact. A recently completed study provides this background information (P. Marler and V. Sherman, unpublished data). Five males of each species were collected in the field as newly laid eggs and hatched in the

\section{EARLY-DEAFENED}

TYPE B

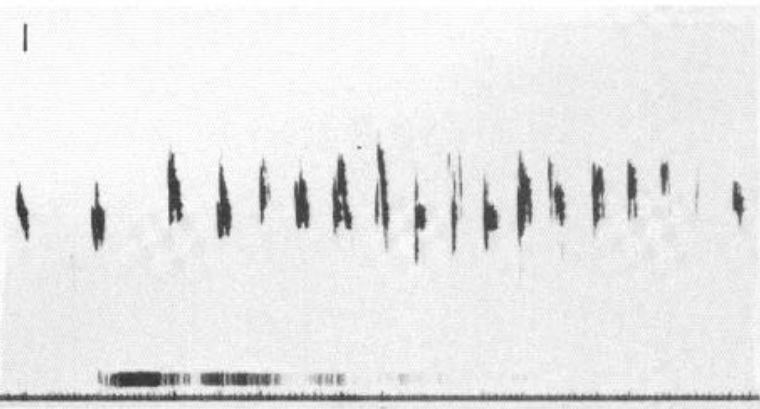

\section{TYPE A}

\section{3}
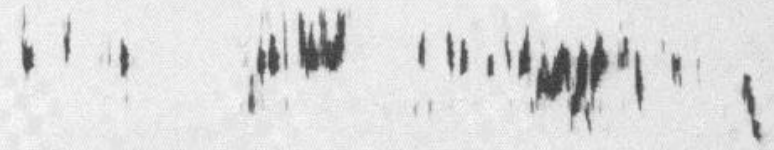

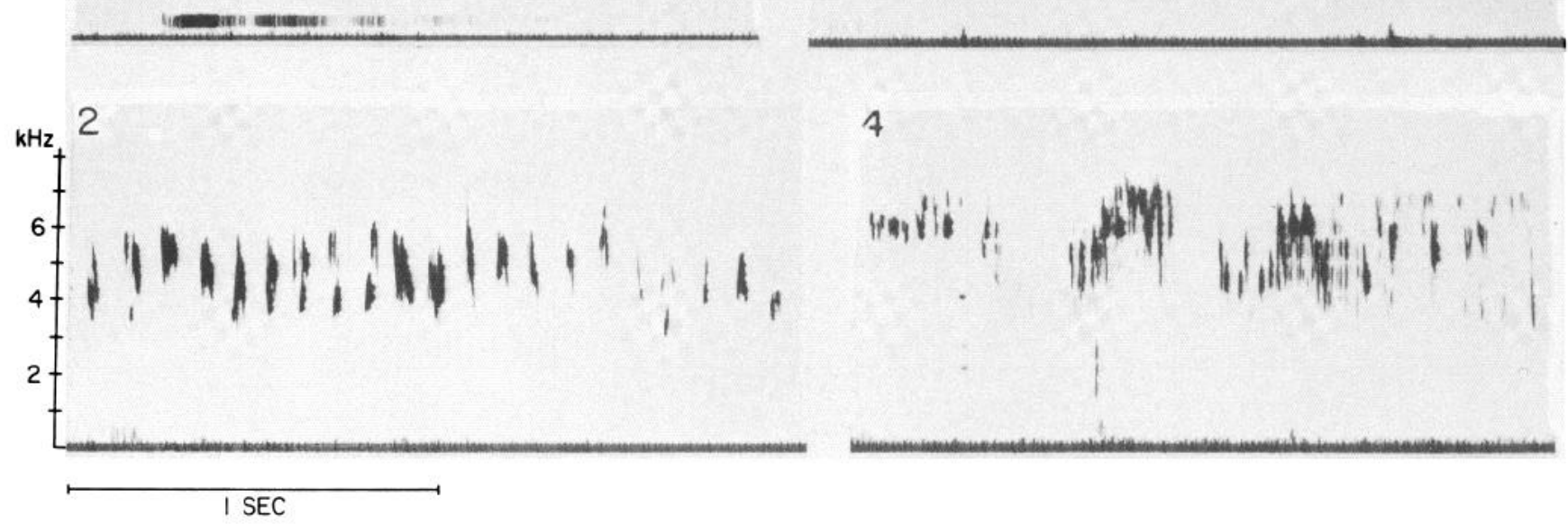

Figure 3. Two consecutive songs of one type (1 and 2) and two consecutive songs of a second type (3 and 4$)$ of deaf male swamp sparrow SW 225, illustrating the unambiguous distinctions between song types. Song type labels coincide with those in Figure 1. The frequency scale is marked in 1-kHz intervals. A 1-sec time marker is indicated. 


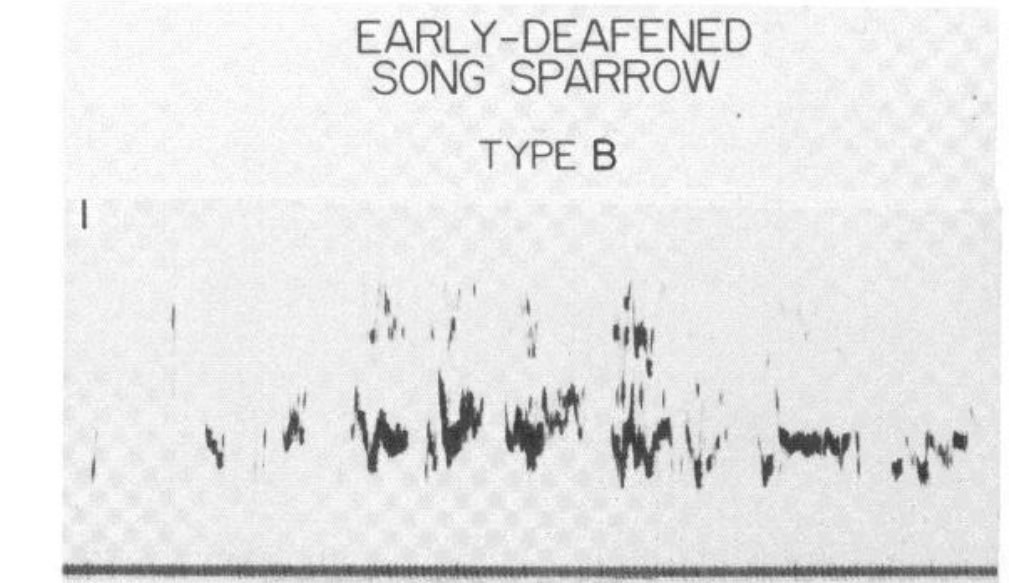

2

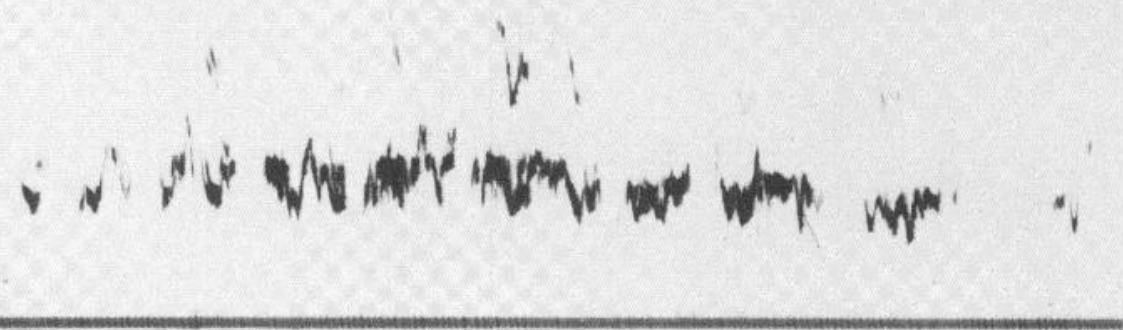

TYPE A

3
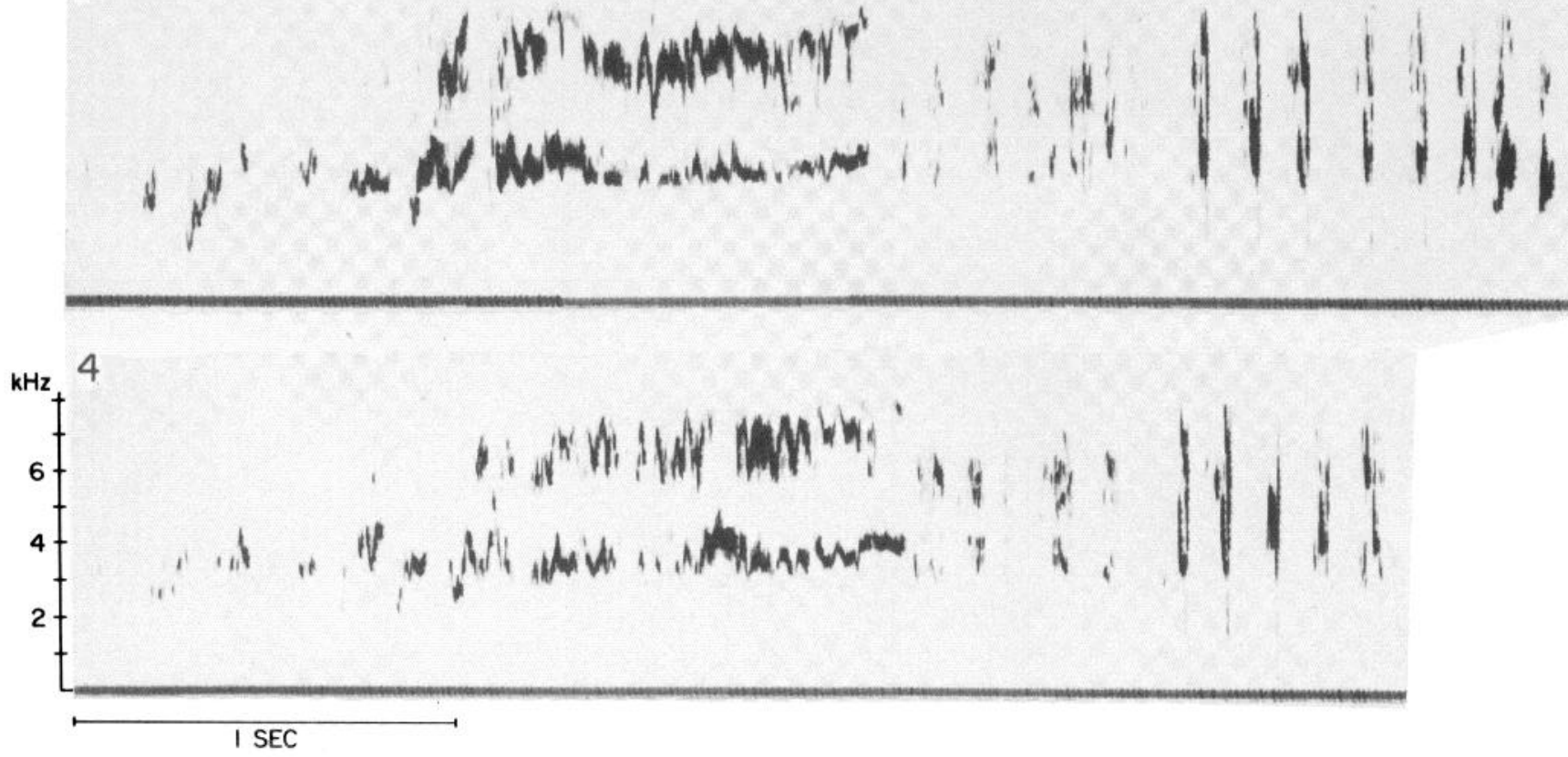

Figure 4. Two consecutive songs of one type ( 1 and 2 ) and two consecutive songs of a second type ( 3 and 4 ) of deaf male song sparrow SG 210. Song types are labeled as in Figure 2. The distinction between song types is clear and unambiguous.

laboratory under canary foster parents. They were taken from their foster parents at about 10 days of age and reared by hand. These 10 birds were thus raised in complete isolation from normal song of their species. As will be reported elsewhere, the songs of both species were simpler than normal. Nevertheless, many innate speciesspecific differences emerged. We shall refer to these vocalizations as "innate songs." A comparison between them and the songs of early deafened birds reared under the same laboratory conditions provides a means of judg- 


\section{YEAR 1}

Type A

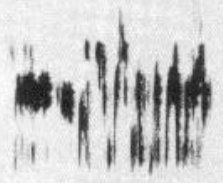

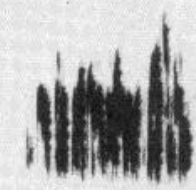
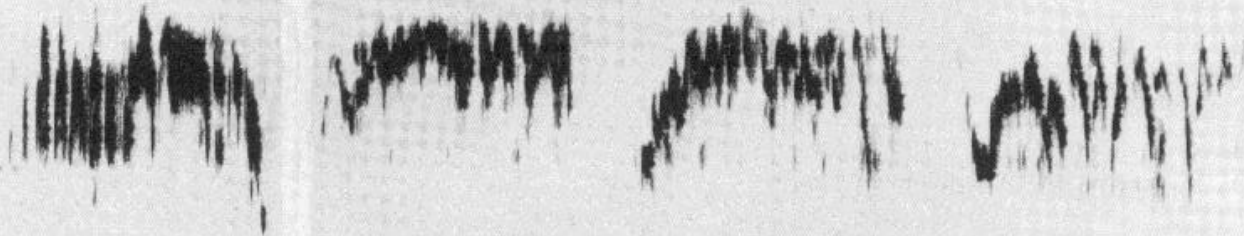
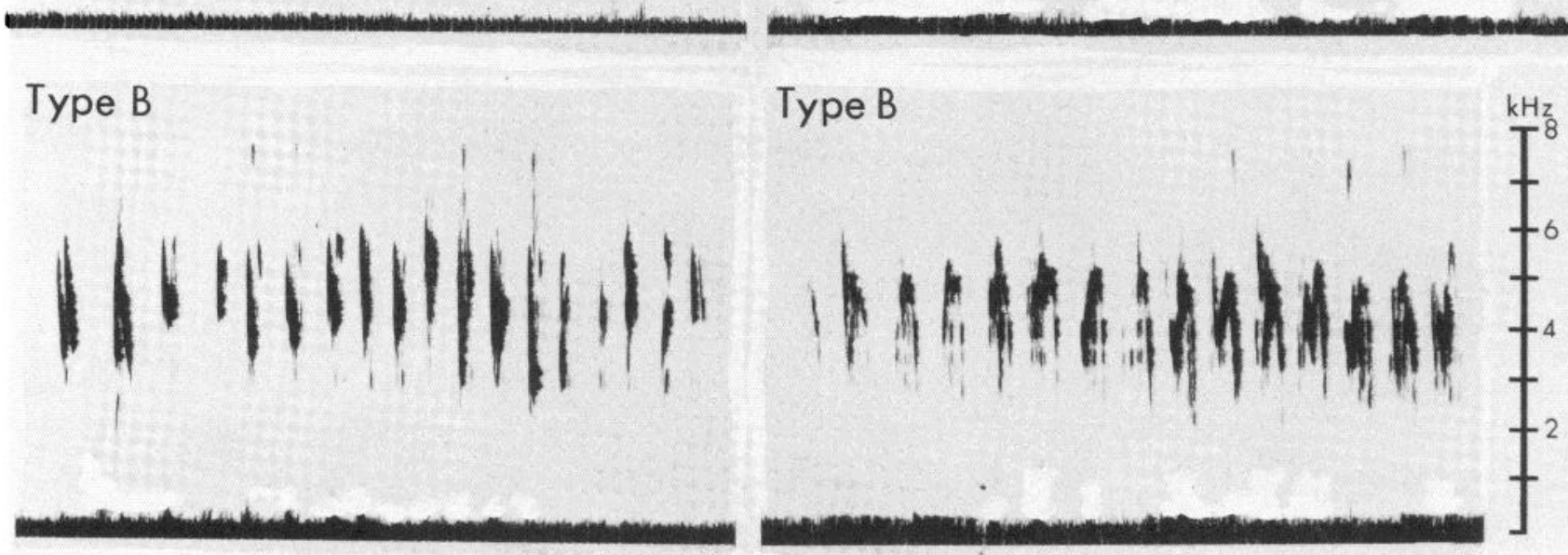

\section{SEC}

Figure 5. Deaf sparrow songs are stable from year to year. Examples of song types $A$ and $B$ of deaf male swamp sparrow SW 225 at 1 and 2 years of age.

ing the impact of opening the auditory feedback loop on the species specificity of song development.

Repertoires. In nature the song repertoires of male swamp sparrows in upper New York State average three to five songs per bird. Repertoires of song sparrows in the same area are 2 to 3 times larger. As shown in Table IV, a difference in the same direction appears in the innate songs. Innate repertoires averaged 1.6 and 5.0 song types per bird in swamp and song sparrows, respectively.

Early deafened swamp sparrows developed repertoires of either one or two song types, with an average of 1.5 per male (Table IV). By contrast, the two early deafened male song sparrows had song repertoires of two and five $(\overline{\mathrm{X}}=3.5)$, a difference that is not statistically significant but that indicates the same trend as the innate song repertoires.

Segmentation. Perhaps the most striking difference between normal songs of swamp and song sparrows lies in the degree to which the song is broken up into distinct parts. A song sparrow song is always multipartite. Treating trills and note complexes as separate parts, a sound spectrogram can always be divided into several distinct segments (Fig. 6). By contrast, a normal swamp sparrow song is one-parted, consisting of a single trill. A similar contrast is evident in innate songs of the two species, although the variability is considerably greater. Whereas natural swamp sparrow songs virtually all consist of a single segment, the innate songs of this species ranged from one to four segments, with an average of 2.2 segments per song. Innate song sparrow songs ranged from one to seven segments, with an average of 3.5 segments per song.

All songs in the "bout transition samples" from the deaf birds were broken down into segments. The variability of syllabic structure complicated the process and, as indicated under "Materials and Methods," some empirical rules were set up to differentiate one segment from another. These rules were applied in identical fashion to songs of both species, as illustrated in Figure 6. The results reveal differences in the degree of song segmentation in the two species. The difference is in the same direction as in the innate songs. Deaf swamp sparrow songs ranged from one to four segments, with an average of 1.6 segments per song. Deaf song sparrows ranged from one to seven segments, with an average of 3.2 segments per song. With the small number of song sparrow subjects and the great variability of their songs, the difference is only marginally significant $(p=0.07$, see Table III). Nevertheless, the tendency to retain species-specific segmentation patterns is evident in Figure 7 , which displays the data as a series of histograms for samples of natural song, the innate songs, and those of the early deafened birds. Species differences in the degree of segmentation are evident under all three conditions. These results show that, despite the opening of the auditory feedback loop at equivalent stages of ontogeny, 
TABLE II

A breakdown of all first-and second-year songs of deaf swamp (SW) and song (SG) sparrows analyzed by real-time sound spectrography

Episodes of subsong, plastic song, and sequences of calling (S) were set on one side and are not considered further in this paper. Songs were classified into types (A, B, etc.) or as unclassifiable (U).

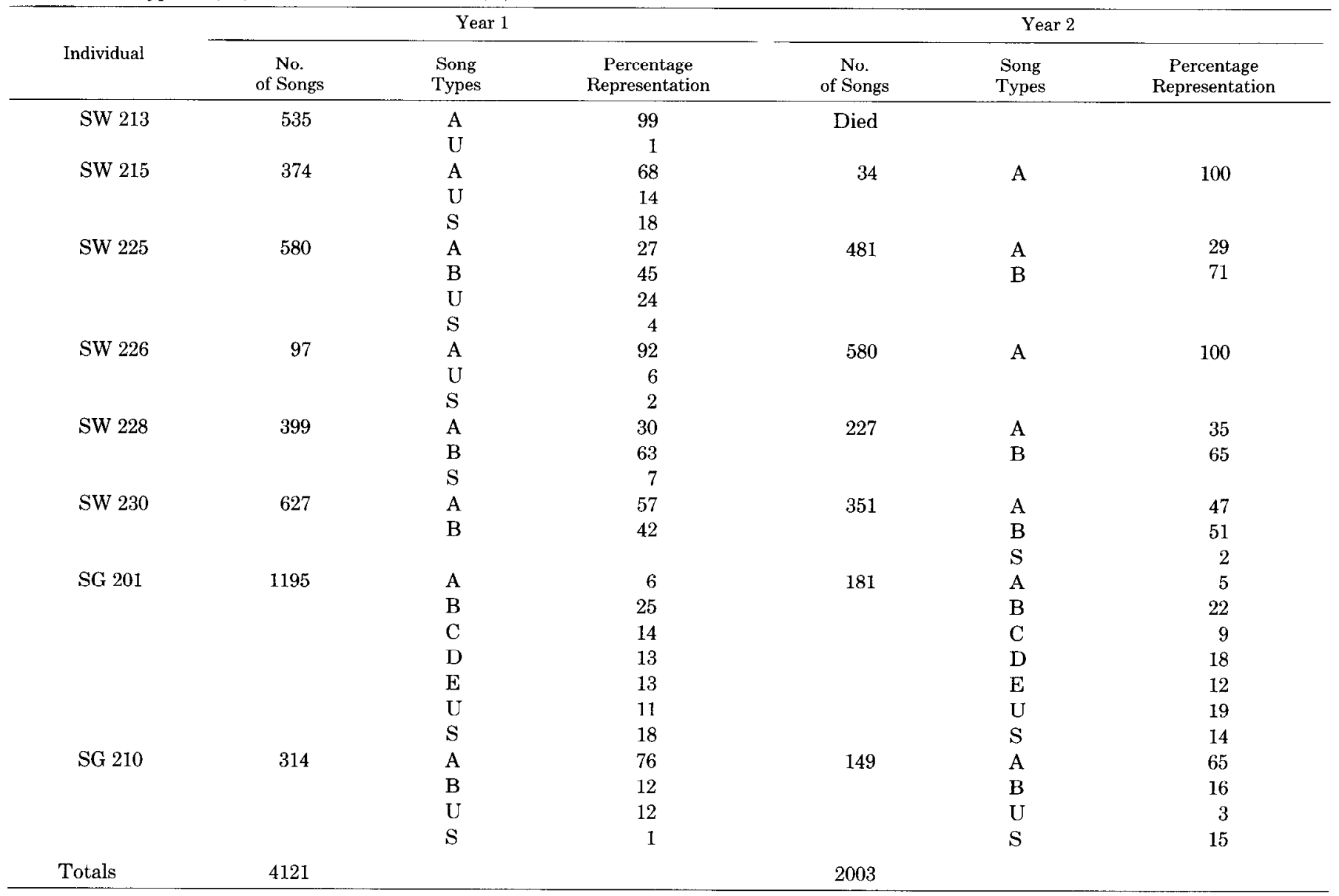

early in life, and prior to the onset of any singing behavior, species-specific developmental trends persist in the song motor patterns of these two species.

Duration and frequency. There is a slight but consistent tendency for natural swamp sparrow songs in the New York area to be shorter than those of song sparrows. For example, 20 randomly chosen swamp sparrow song types averaged $2.25 \mathrm{sec}$, and an equal sample of song sparrow songs averaged $2.66 \mathrm{sec}$. This difference persists in the innate songs, which average $2.01 \mathrm{sec}( \pm 0.29 \mathrm{SD})$ for the swamp sparrows and $2.90 \mathrm{sec}( \pm 0.44 \mathrm{SD})$ for the song sparrows. As shown in Table IV, songs of the early deafened birds, although shorter than the innate songs as a class, also showed a species difference in the same direction. The swamp sparrow songs averaged $1.71 \mathrm{sec}$ $( \pm 0.25 \mathrm{SD})$ and those of the song sparrows averaged 2.73 $\sec ( \pm 1.19 \mathrm{SD})$.

Similarly there is a difference in song pitch in the two species. Song sparrow songs tend to be pitched slightly lower than those of swamp sparrows. A species difference is reflected in measurements of the maximum frequencies in innate song sparrow songs, which are appreciably lower than corresponding values for innate swamp sparrow songs. Values for dominant and minimum song frequencies do not differ significantly (Table IV). Frequency measurements for songs of the deaf sparrows yielded similar trends. In this case, average values for dominant, maximum, and minimum song frequencies were all higher for swamp than for song sparrows (Table IV).

The limited species differences in song duration and frequency hardly rank as highly salient species-specific features, and the overlap is great. Nevertheless, the same contrasts appear in the deaf birds, thus providing a further demonstration of species specificity in song structure after severance of the auditory feedback loop.

Note structure. There are typically more notes in a normal swamp sparrow song than in a song sparrow song. For example, a random selection of 20 swamp sparrow song types averaged 43.5 notes per song, and an equal number of song sparrow songs averaged 23.4 notes per song. Similarly, in the innate songs of the two species there were $19.8 \pm 8.3$ (SD) notes per song for the swamp sparrow, twice as many as in the innate song sparrow songs, with $10.4 \pm 2.1$ (SD) notes per song. When we turn to songs of the deaf birds, however, this species difference disappears. Average counts of notes per song were 12.1 \pm 6.4 for deaf swamp sparrows and $16.6 \pm 7.1$ for deaf song sparrows (Table IV). The duration of individual notes in innate swamp sparrow songs is less than half of that in innate song sparrow songs. This is another species difference that shrinks to insignificance with deafening (Table IV). The impact of auditory deprivation by early 
TABLE III

A comparison of the numbers of segments in the songs of innate and deaf swamp (SW) and song (SG) sparrows

The figures are based on Kay sound spectrograms of the "bout transition" samples of songs described in Table I and the text. Results of MannWhitney U-tests (one-tailed) indicate that the degree of song segmentation in the two species differs significantly in the innate songs ( $p=0.004$ ) and with marginal significance in the deaf songs $(p=0.07)$. Tests were conducted using means for individual subjects, derived by averaging the means in this table. Where individuals have more than one song type, these means are given in brackets below each bird's number. For innate songs, $N=$ five swamp sparrows and five song sparrows. For deaf songs $N=$ six swamp sparrows and iwo song sparrows.

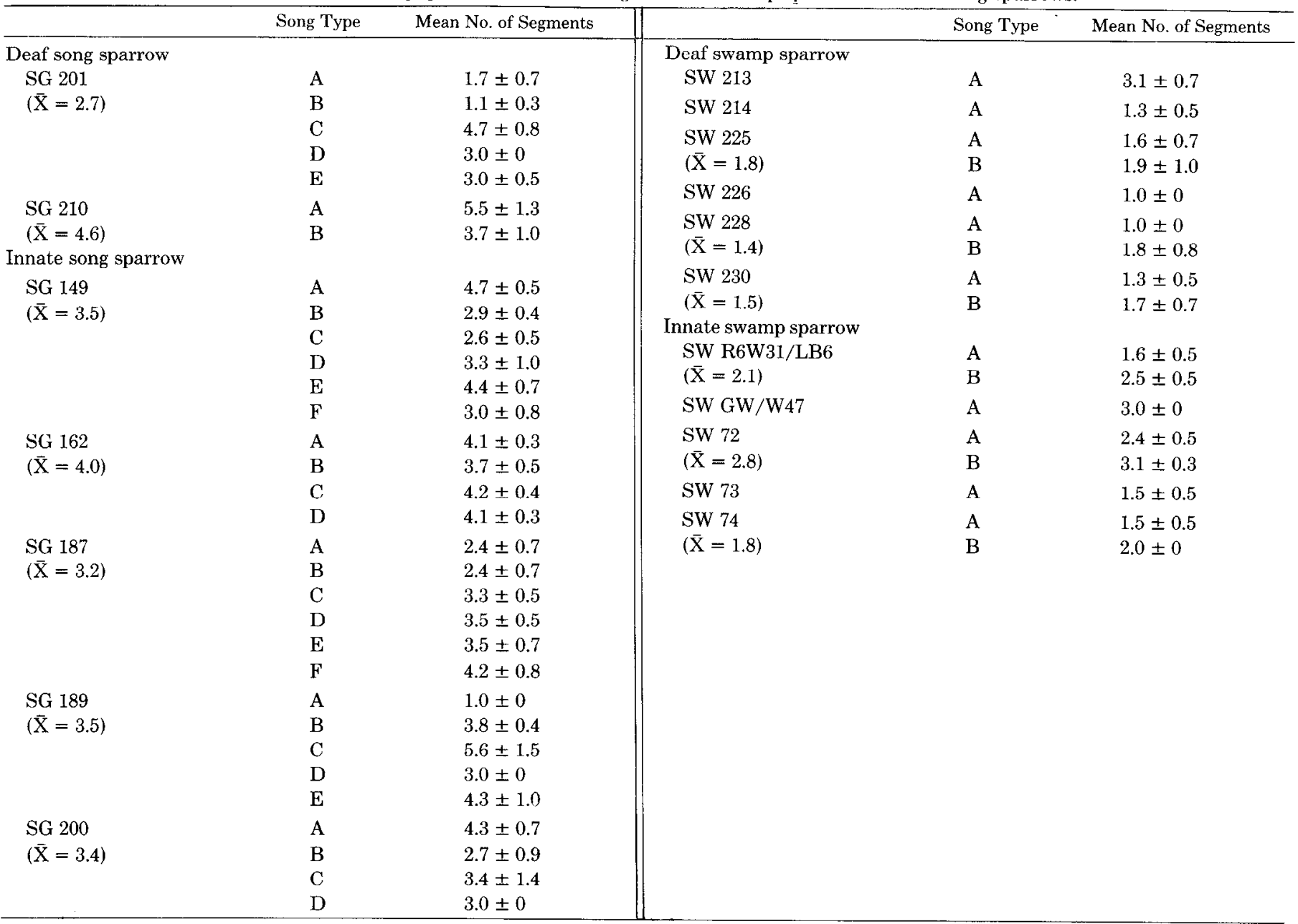

deafening is thus greater on note structure than on the syntactical patterning of the song as a whole.

The temporal structure of deaf songs is not, of course, entirely normal, as is evident in the number of trilled syllables per song. There are considerably more of these in both natural and innate swamp sparrow songs, as compared with the song sparrow. This difference virtually disappears with deafening (Table IV), although this may be partly attributable to the difficulty of delineating syllables in the deaf birds. At present we can only speak with confidence about the grosser aspects of temporal song structure that survive deafening.

The range of variability. However long one searched, it would be hard or impossible to find natural swamp and song sparrow songs so similar that their species identity would be uncertain. Species differences in song organization and syllabic structure are pervasive and consistent. The same appears to be true of the innate songs of these two species, although a case can be made that the degree of contrast is reduced. When we come to the songs of the deaf birds, species differences in such features as song segmentation are still evident, although the overlap is greater than in either natural or innate songs of the two species. Thus, although one can select some songs from deaf individuals of the two species that exhibit a high degree of species specificity (Fig. $8 B$ ), it is also possible to select other songs in which species specificity is minimal (e.g., Fig. 8A). In fact, the similarity of the two particular song types in Figure 8 is so great that one suspects the lack not only of species specificity but of individuality as well.

Thus, along with the demonstration of persistence of species specificity in songs of early deafened sparrows, it is also important to emphasize the reduction in species specificity represented by the high degree of overlap in their song motor patterns. Although the capacity for developing certain species-specific structural song features is clearly present in early deafened birds, some individuals barely realize that capacity, if at all.

\section{Discussion}

This study was designed to determine whether songbirds deafened in infancy prior to any singing activity would produce songs that are virtually structureless, with 
TABLE IV

A comparison of song duration, number and duration of notes, number of trilled syllables per song, various frequency measures, and the number of song types in innate and deaf songs of swamp and song sparrows

All measures for the deaf birds (two song sparrows, five swamp sparrows) are based on sound spectrograms of the "bout transition samples" as described in Table I and the text. Data for innate songs are from a similarly drawn sample of five swamp sparrows (76 exemplars of eight song types) and five song sparrows (219 exemplars of 25 song types). Measurements of song duration, notes per song, and trilled syllables per song were averaged for each song type, and the average of the averages was calculated for each species with standard deviations. In cases where an individual had more than one song type, the average of its song types was used. Note durations and frequency measurements were taken for each note, averaged per song, and then treated as above. Average numbers of song types per individual are indicated at the bottom.

\begin{tabular}{llcc}
\hline & & Deaf & Innate \\
\hline Song duration & Song & $2.732 \pm 1.194$ & $2.898 \pm 0.439$ \\
(sec) & Swamp & $1.706 \pm 0.248$ & $2.006 \pm 0.292$ \\
Notes per song & Song & $16.6 \pm 7.1$ & $10.4 \pm 2.1$ \\
& Swamp & $12.1 \pm 6.4$ & $19.8 \pm 8.3$ \\
Note duration & Song & $0.190 \pm 0.112$ & $0.232 \pm 0.034$ \\
(sec) & Swamp & $0.221 \pm 0.210$ & $0.092 \pm 0.072$ \\
Trilled syllables & Song & $10.4 \pm 3.0$ & $7.6 \pm 1.9$ \\
per song & Swamp & $7.2 \pm 5.7$ & $17.7 \pm 8.8$ \\
Dominant frequency & Song & $3617 \pm 313$ & $4110 \pm 325$ \\
(Hz) & Swamp & $4860 \pm 348$ & $4550 \pm 469$ \\
Maximum frequency & Song & $5757 \pm 303$ & $5070 \pm 282$ \\
(Hz) & Swamp & $6391 \pm 369$ & $6378 \pm 837$ \\
Minimum frequency & Song & $2201 \pm 110$ & $2950 \pm 278$ \\
(Hz) & Swamp & $3411 \pm 661$ & $2708 \pm 561$ \\
Number of song types & Song & $3.5 \pm 2.1$ & $5.0 \pm 1.0$ \\
& Swamp & $1.5 \pm 0.5$ & $1.6 \pm 0.5$ \\
\hline
\end{tabular}

species-specific features reduced to a minimum or lacking altogether. The prediction was not confirmed. The issue of species specificity was approached comparatively by selecting as subjects two closely related species with songs that differ significantly in acoustic structure, living within earshot of one another, each confronted in nature with a need to discriminate between its own and other species' songs. Swamp and song sparrows satisfy these conditions.

As a basis for comparison, deaf birdsongs were referred not only to natural motor patterns, but most importantly to the innate songs developed when members of the two species were reared from the egg in the laboratory, in isolation from all adult song. To determine the impact of opening the auditory feedback loop on song structure, males were deafened in infancy at equivalent stages of vocal development, prior to the production of any song whatsoever.

The motor patterns produced were highly variable and degraded in certain respects. Nevertheless, the use of a comparative approach revealed a significant number of species-specific coordinations. By species specificity we imply not only that features were approximately normal, but also that they differed across species in the same direction as in natural and innate songs. These critical features include song repertoire size, song duration, certain frequency characteristics, and most importantly the degree of segmentation of the song pattern. Motor patterns of the two species differ most conspicuously in this regard. By presenting wild sparrows with natural and synthetic patterns, we have shown that, for the song sparrow, the degree of segmentation makes an important contribution to the process of song discrimination in nature (Searcy et al., 1981). The natural song of the swamp sparrow consists of a single segment, whereas that of the song sparrow is multisegmental. The songs of early deafened song sparrows are more segmented than those of swamp sparrows reared under the same conditions.

The auditory template theory of song learning derived from Konishi's demonstration that early deafening results in more degraded motor patterns of singing than those produced by songbirds with their sense of hearing intact, irrespective of whether normal conspecific song has been experienced (Konishi, 1964, 1965a, b). The notion of acquired auditory templates is not at issue in the present study, but the innate auditory template hypothesis is. This hypothesis derives from the greater degradation of deaf songs as compared with innate songs. In its strongest form it predicts loss of the species-specific features of the innate song after early deafening. The persistence of some species-specific song traits after early deafening, as in the black-headed grosbeak and the Oregon junco, raised difficulties for this version of the auditory template theory, although, as Nottebohm (1966, 1968) suggested, residual song structure might have been a consequence of the achievement by these subjects of some song structure prior to deafening. In the present experiments, deafening was imposed earlier in life than in Nottebohm's chaffinches and earlier than in all but two of Konishi's subjects (two robins). In none of our subjects was there any song experience prior to deafening. Thus, our results point to an endogenous capacity to generate some species-specific structure, irrespective of whether the bird can hear its own voice, as indicated by some of Konishi's earlier results.

A still further degree of deprivation from auditory feedback has been achieved with young canaries reared in high level white noise, sufficient to mask their own voices and those of parents (Marler et al., 1973; Marler and Waser, 1977). At weaning, around 30 days of age, the canaries were removed from the noise and immediately deafened. Despite the virtually total occlusion of the auditory pathway for vocal feedback, a significant number of species-specific features persisted. Güttinger (1981) reconfirmed this by further analysis of taped songs of the same subjects. As in song and swamp sparrows, species specificity is particularly evident in the bout structure of deaf canary singing, with features that recur in the songs of related species (Güttinger, 1979; Güttinger et al., 1978).

The songs of early deafened cardinals, Cardinalis car. dinalis, red-winged blackbirds, Agelaius phoeniceus, and zebra finches, Taeniopygia guttata, all retain some normal features, despite the abnormality of their fine structure (Dittus and Lemon, 1970; Marler et al., 1972; Price, 1979). Thus, in an appreciable number of birds the vocal motor system has the intrinsic capacity to develop patterned species-specific songs without auditory feedback from singing activity. The possibility remains open that feedback from presinging vocal productions, such as begging calls, plays some role. It seems likely, as Nottebohm (1972) has suggested, that presinging sensorimotor ex- 


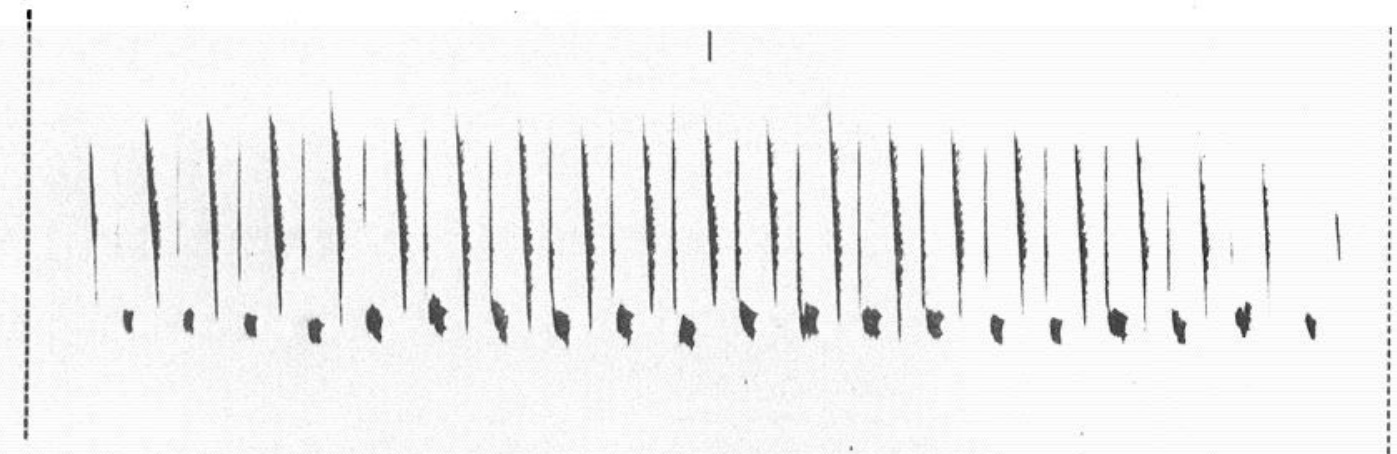
A
GEORGIANA - NORMAL
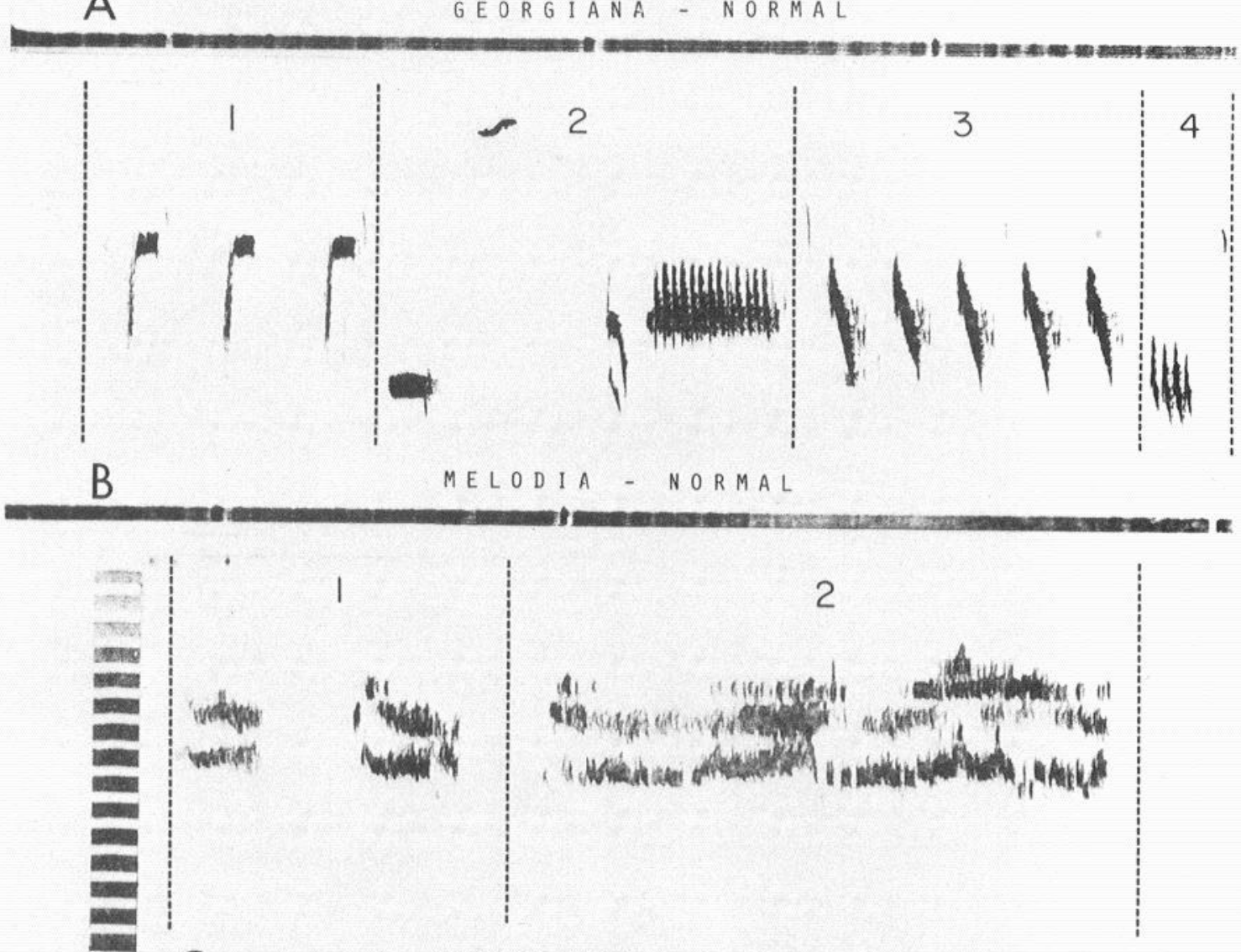

GEORGIANA - DEAF

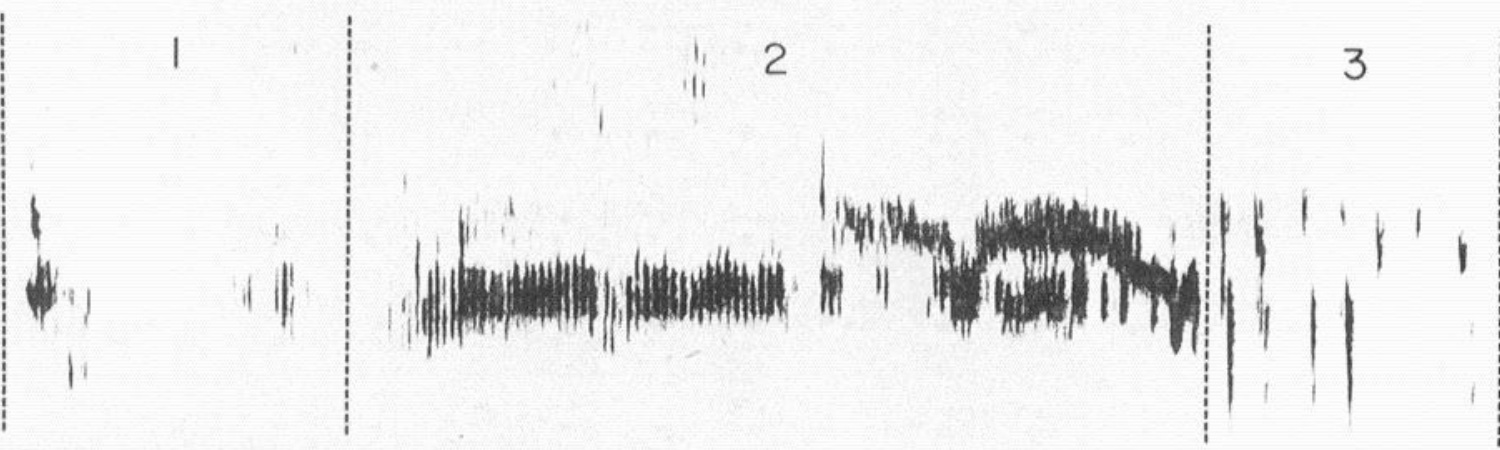

D

MELODIA - DEAF

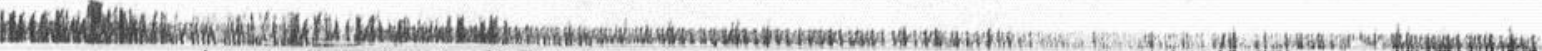

Figure 6. Illustrations of the method used to segment song patterns of deaf birds $(C$ and $D)$. Normal swamp (georgiana) and song sparrow (melodia) songs are shown for comparison $(A$ and $B)$. In the normal song sparrow song, segments 1 and 3 qualify as "trills" and segments 2 and 4 as "note complexes." In the deaf song sparrow song, segments 1 and 3 qualify as trills and segment 2 as a note complex. See the text for more details. 

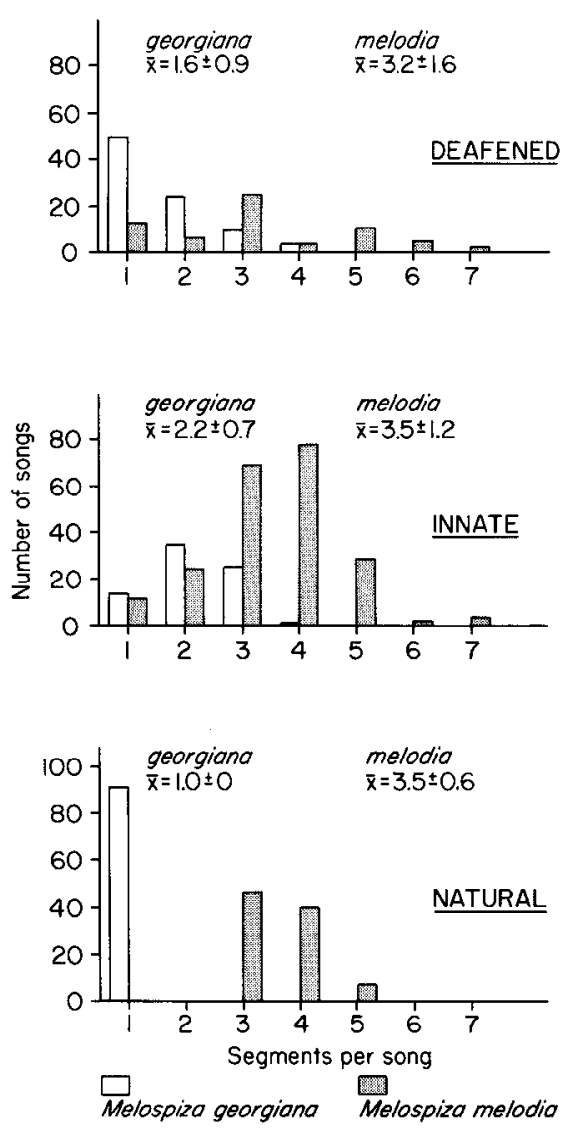

Figure 7. Song and swamp sparrow songs: histograms of the numbers of segments per song for samples of natural and innate songs and songs of early deafened birds. Deaf swamp sparrows (georgiana) are represented by 88 examples of nine song types from six males. Deaf song sparrow (melodia) data consist of 67 examples of seven song types from two males. The innate swamp sparrow songs are 76 examples of eight song types from five males. The innate song sparrow sample consists of 219 examples of 25 song types from five males. Normal swamp sparrow songs are 92 examples of 10 song types from five males. The normal song sparrow songs are 93 examples of 10 song types from three males.

perience with begging calls contributes to the acquisition of general skills in the use of the vocal apparatus but is only indirectly relevant to the production of speciesspecific song structure. The canaries studied by Marler and Waser (1977) and Güttinger (1981) developed species-specific song structure despite being reared in masking noise and thus deprived of all patterned auditory input, including feedback from begging and fledgling calls.

What kind of brain mechanisms generate this patterning? One logical possibility is a sensory template that is responsive to proprioceptive feedback from the vocal apparatus (cf. Konishi, 1964). Although often mentioned as a possibility, this alternative still awaits study. Now that afferent fibers from the syrinx have been identified and shown to be accessible to sectioning (Bottjer and Arnold, 1981), the way is open for future experiments. Another possibility is that patterns of air flow through the syrinx are finely controlled, perhaps by involvement of the respiratory musculature (Nottebohm, 1975; Güttinger, 1981). Such control mechanisms could involve not only the abdominal and other respiratory musculature, but oral mechanisms as well. A third possibility is patterned motor outflow directly from the central nervous system to the intrinsic syringeal musculature. None of these possibilities is mutually exclusive.

Present results show that nonauditory sources of patterned motor production make a significant contribution to the ontogeny of some birdsongs. Thus the strongest form of the innate auditory template hypothesis, with its prediction of virtually structureless song after opening of the auditory feedback loop (e.g., Nottebohm, 1966, 1968; Nottebohm et al., 1976; Marler, 1976, 1981; Bentley and Konishi, 1978; Konishi, 1978) is not tenable in these two sparrows. Nevertheless, their ability to hear their own voices plays a vital role in song development. The song structure that develops after early deafening occurs primarily in the gross syntactical organization and certain frequency characteristics. At the level of the fine structure of notes and syllables, the degradation of songs of early deafened sparrows is very much in evidence. A species difference in both natural and innate songs in the number of notes per song virtually disappears after early deafening. Another contrast that is lost after deafening is a species difference in note duration.

In addition to quantitative aspects of song structure, it is obvious from qualitative inspection of sound spectrograms that the constituent notes of songs of early deafened sparrows are highly abnormal. Indeed, organized note structure appears to be virtually eliminated by early deafening (cf. Konishi and Noltebohm, 1969). Note durations, temporal features, spectral structure, and patterns of frequency modulation vary widely and unpredictably from bird to bird, subject only to the most general frequency constraints. It is this extreme variability that makes the underlying syntax of the songs of deaf birds so hard to discern. In future emendations of the auditory template hypothesis it will be appropriate to focus attention especially on the notes and syllables from which songs are constructed.

Perhaps the most remarkable and perplexing of our results is the range of alternative motor patterns displayed by different individuals of the same species reared under identical conditions. In some the motor patterns come surprisingly close to normal, even in their fine structure (e.g., SW 230, Type A, Fig. 1). In others, songs are so degraded that almost all species differences are lost (e.g., Fig. 8, $A$ and $B$ ). Looking for other behavioral correlates of this variation, deafening predated all singing activity, but there might have been individual differences in predeafening experience of begging call production. This was not recorded in the present study. The occurrence of both degraded and structured song motor patterns in the same individual suggests that such a correlation is unlikely. There might be a relationship between the rate of progression from subsong to crystallization of different themes and the degree of song structure achieved by deaf birds. Otherwise, it remains as something of a mystery why some songs conform closely to the predictions of the strong form of the innate auditory template hypothesis while others do not. 


\section{EARLY-DEAFENED}
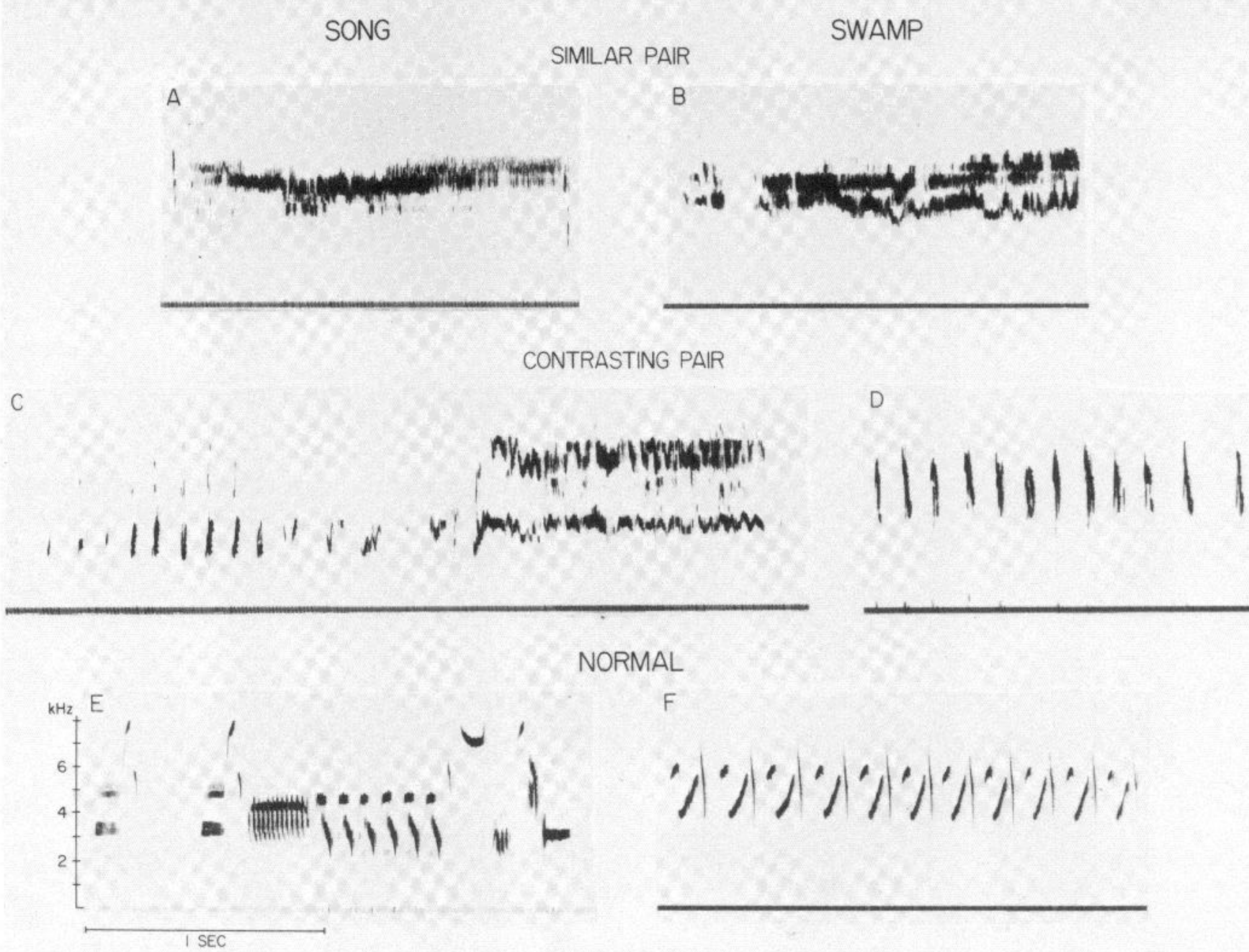

Figure 8. Two pairs of songs of deaf swamp and song sparrows selected to display minimal $(A$ and $B)$ and maximal $(C$ and $D)$ species specificity. Two normal songs $(E$ and $F)$ are also presented for comparison.

\section{References}

Bentley, D., and M. Konishi (1978) Neural control of behavior. Annu. Rev. Neurosci. 1: 35-59.

Bottjer, S. W., and A. P. Arnold (1981) Identification of afferent neurons in the hypoglossal nerve of the zebra finch. Neurosci. Abstr. 93: 7.

Dittus, W. P. J., and R. E. Lemon (1970) Auditory feedback in the singing of cardinals. Ibis 112: 544-548.

Güttinger, H. R. (1979) The integration of learnt and genetically programmed behaviour: A study of hierarchical organization in songs of canaries, greenfinches and their hybrids. Z. Tierpsychol. 59: 285-303.

Güttinger, H. R. (1981) Self-differentiation of song organization rules by deaf canaries. Z. Tierpsychol. 56: 323-340.

Güttinger, H. R., J. Wolffgramm, and F. Thimm (1978) The relationship between species specific song programs and individual learning in songbirds: A study of individual variation in songs of canaries, greenfinches, and hybrids between the two species. Behavior 65: 241-262.

Hüchtker, R., and J. Schwartzkopff (1958) Soziale Verhaltensweisen bei hörenden und gehörlosen Dompfaffen (Pyrrhu: pyrrhula L.). Experientia 14: 106-107.

Konishi, M. (1963) The role of auditory feedback in the vocal behavior of the domestic fowl. Z. Tierpsychol. 20: 349-367.
Konishi, M. (1964) Effects of deafening on song development in two species of juncos. Condor 66: 85-102.

Konishi, M. (1965a) Effects of deafening on song development in American robins and black-headed grosbeaks. Z. Tierpsychol. 22: 584-599.

Konishi, M. (1965b) The role of auditory feedback in the control of vocalization in the white-crowned sparrow. Z. Tierpsychol. 22: $770-783$.

Konishi, M. (1978) Auditory environment and vocal development in birds. In Perception and Experience, R. D. Walk and H. L. Pick, eds., pp. 105-118, Plenum Press, New York.

Konishi, M., and F. Nottebohm (1969) Experimental studies on the ontogeny of avian vocalizations. In Bird Vocalizations, R. A. Hinde, ed., pp. 29-48, Cambridge University Press, Cambridge.

Marler, P. (1964) Inheritance and learning in the development of animal vocalizations. In Acoustic Behavior of Animals, M. C. Busnel, ed., pp. 228-243, Elsevier, Amsterdam.

Marler, P. (1970) A comparative approach to vocal learning: Song development in white-crowned sparrows. J. Comp. Physiol. Psychol. 71, Suppl. 1-25.

Marler, P. (1976) Sensory templates in species-specific behavior. In Simpler Networks and Behavior, J. Fentress, ed., pp. 314-329, Sinauer Associates, Sunderland, Mass.

Marler, P. (1981) Birdsong: The acquisition of a learned motor 
skill. Trans. Neurosci. 4: 88-94.

Marler, P., and S. Peters (1980) Birdsong and speech: Evidence for special processing. In Perspectives on the Study of Speech, P. Eimas and J. Miller, eds., pp. 75-112, Lawrence Erlbaum Associates, Hillsdale, NJ.

Marler, P., and S. Peters (1982) Structural changes in song ontogeny in the swamp sparrow, Melospiza georgiana. Auk 99: 446-458.

Marler, P., and M. Tamura (1964) Culturally transmitted patterns of vocal behavior in sparrows. Science 146: 1483-1486.

Marler, P., and M. S. Waser (1977) The role of auditory feedback in canary song development. J. Comp. Physiol. Psychol. 91: 8-16.

Marler, P., P. Mundinger, M. S. Waser, and A. Lutjen (1972) Effects of acoustical stimulation and deprivation on song development in the red-winged blackbird (Agelaius phoeniceus). Anim. Behav. 20: 586-606.

Marler, P., M. Konishi, A. Lutjen, and M. S. Waser (1973) Effects of continuous noise on avian hearing and vocal development. Proc. Natl. Acad. Sci. U. S. A. 70: 1393-1396.

Messmer, E., and I. Messmer (1956) Die Entwicklung der Lautäusserungen und einiger Verhaltensweisen der Amsel (Turdus merula merula L.) unter natürlichen Bedingungen und nach Einzelaufzucht in schalldichten Räumen. Z. Tierpsychol. 13: 341-441.

Mulligan, J. A. (1966) Singing behavior and its development in the song sparrow, Melospiza melodia. Univ. of California, Berkeley, Publ. Zool. 81: 1-76.

Nottebohm, F. (1966) The role of sensory feedback in the development of avian vocalizations. Ph.D. 'I'hesis, University of California, Berkeley.
Nottebohm, F. (1967) The role of sensory feedback in the development of avian vocalizations. In Proceedings of the XIVth International Ornithological Congress, D. W. Snow, ed., pp. 265-280, Blackwell, Oxford.

Nottebohm, F. (1968) Auditory experience and song development in the chaffinch, Fringilla coelebs. Ibis 110: 549-568.

Nottebohm, F. (1972) Neural lateralization of vocal control in a passerine bird. II. Subsong, calls and a theory of vocal learning. J. Exp. Zool. 179: 35-49.

Nottebohm, F. (1975) Vocal behavior in birds. In Avian Biology, D. Farner, ed., Vol. V, pp. 287-332, Academic Press, New York.

Nottebohm, F., and M. Nottebohm (1971) Vocalizations and breeding behavior of surgically deafened ring doves, Streptopelia risoria. Anim. Behav. 19: 313-327.

Nottebohm, F., T. M. Stokes, and C. M. Leonard (1976) Central control of song in the canary, Serinus canarius. J. Comp. Neurol. 165: 457-486.

Price, P. H. (1979) Developmental determinants of structure in zebra finch song. J. Comp. Physiol. Psychol. 93: 260-277.

Schleidt, W. M. (1964) Über die Spontaneität von Erbkoordinationen. Z. Tierpsychol. 21: 235-356.

Schwartzkopff, J. (1949) Über Sitz und Leistung von Gehör und Vibrationssinn bei Vögeln. Z. Vgl. Physiol. 31: 527-608.

Searcy, W. A., P. Marler, and S. Peters (1981) Species song discrimination in adult female song and swamp sparrows. Anim. Behav. 29: 997-1003.

Thielcke, H., and G. Thielcke (1960) Akustisches Lernen verschiedener alter schallisolierter Amseln (Turdus merula L.) und die Entwicklung erlernter Motive ohne und mit künstlichem Einfluss von Testosteron. Z. Tierpsychol. 17: 211-244. 